\title{
Exploring the role of ionospheric drivers during the extreme solar minimum of 2008
}

\author{
J. Klenzing ${ }^{1}$, A. G. Burrell ${ }^{2}$, R. A. Heelis ${ }^{3}$, J. D. Huba ${ }^{4}$, R. Pfaff ${ }^{1}$, and F. Simões ${ }^{1}$ \\ ${ }^{1}$ Space Weather Lab/Code 674, Goddard Space Flight Center, Greenbelt, MD, USA \\ ${ }^{2}$ Department of Atmospheric, Oceanic, and Space Sciences, University of Michigan, Ann Arbor, MI, USA \\ ${ }^{3}$ William B. Hanson Center for Space Sciences, The University of Texas at Dallas, Richardson, TX, USA \\ ${ }^{4}$ Plasma Physics Division, Naval Research Laboratory, Washington, DC, USA
}

Correspondence to: J. Klenzing (jeffrey.klenzing@nasa.gov)

Received: 20 June 2013 - Revised: 28 October 2013 - Accepted: 5 November 2013 - Published: 4 December 2013

\begin{abstract}
During the recent solar minimum, solar activity reached the lowest levels observed during the space age, resulting in a contracted atmosphere. This extremely low solar activity provides an unprecedented opportunity to understand the variability of the Earth's ambient ionosphere. The average $\boldsymbol{E} \times \boldsymbol{B}$ drifts measured by the Vector Electric Field Instrument (VEFI) on the Communications/Navigation Outage Forecasting System (C/NOFS) satellite during this period are found to have several differences from the expected climatology based on previous solar minima, including downward drifts in the early afternoon and a weak to nonexistent pre-reversal enhancement. Using SAMI2 (Sami2 is Another Model of the Ionosphere) as a computational engine, we investigate the effects of these electrodynamical changes as well as the contraction of the thermosphere and reduced EUV ionization on the ionosphere. The sensitivity of the simulations to wind models is also discussed. These modeled ionospheres are compared to the C/NOFS average topside ion density and composition and Formosa Satellite3/Constellation Observing System for Meteorology, Ionosphere, and Climate average $N m \mathrm{~F} 2$ and $h m \mathrm{~F} 2$. In all cases, incorporating the VEFI drift data significantly improves the model results when compared to both the C/NOFS density data and the F3/C GOX data. Changing the MSIS and EUVAC models produced changes in magnitude, but not morphology with respect to local time. The choice of wind model modulates the resulting topside density and composition, but only the use of the VEFI $\boldsymbol{E} \times \boldsymbol{B}$ drifts produces the observed post-sunset drop in the F peak.
\end{abstract}

Keywords. Ionosphere (equatorial ionosphere; ion chemistry and composition; modeling and forecasting)

\section{Introduction}

The recent solar minimum between cycles 23 and 24 has proved to be an unusual time for space physics. Solar activity reached the lowest levels observed during the space age (Araujo-Pradere et al., 2011). The thermospheric density was found to reach a record low, based on the analysis of the orbital decay of numerous satellites (Emmert et al., 2010) and by in situ measurement of the neutral scale height (Haaser et al., 2010). The topside ionosphere is similarly contracted, as demonstrated by Heelis et al. (2009) and Klenzing et al. (2011b).

The exact nature of the Extreme Ultraviolet (EUV) fluxes during this minimum has been the subject of much discussion. Long-term measurements of EUV from the SOHO mission show that the $30.4 \mathrm{~nm}$ flux is lower by $15 \%$ during the 2007-2009 minimum versus the previous minimum (Solomon et al., 2010). Further simulations using the Thermosphere Ionosphere Electrodynamics General Circulation Model (TIEGCM) show that the expected contributions toward the anomalous thermospheric contraction by increased $\mathrm{CO}_{2}$ (Solomon et al., 2011) and decreased geomagnetic inputs (Deng et al., 2012) are expected to be smaller than that of the reduced EUV input. However, studies of global Total Electron Content (TEC) patterns have suggested that the total ion production during the recent minimum is similar to that of the previous minimum (Lean et al., 2011). Additionally, the complicated response of ionosonde data as a function of geophysical location suggests that an equally complicated change in the plasma drift and neutral winds is present during this unique minimum (Araujo-Pradere et al., 2011). 
Ionospheric irregularities are also observed to be significantly different during the extreme solar minimum. Equatorial Spread-F (ESF) is a signature in ionosonde data related to the propagation of radio waves through a corrugated ionopshere; these signatures are frequently equated with equatorial plasma bubbles and typically decrease with decreasing solar activity. However, during the extreme solar minimum, ESF signatures increased over the Brazilian sector in the absence of plasma bubbles (Candido et al., 2011). These features were coincident with Medium-Scale Travelling Ionosphere Disturbances (MSTIDs) observed in nearby imager data. Additionally, plasma density enhancements (also known as plasma blobs) were frequently observed by the C/NOFS satellite in 2009 and were found to have significantly different perturbation plasma drifts relative to the density structure than previously observed during periods of higher solar flux (Klenzing et al., 2011a). This change in structure suggests that the observed enhancements are a manifestation of wave action in the lower thermosphere. In order to understand these unusual irregularities, the new baseline ionosphere in which they appear must first be understood.

The SAMI2 model (Huba et al., 2000) is used as a computational engine to understand the relative contributions of changes in neutral density, ionizing EUV, and $\boldsymbol{E} \times \boldsymbol{B}$ drifts to the resultant ionosphere. The perturbations to these three components are analyzed based on the results of the studies mentioned above. The test cases are run near the December solstice of 2008, which corresponds to the deepest part of the extreme solar minimum.

The C/NOFS satellite is part of a space weather mission led by the US Air Force Research Laboratory to locate, understand, and predict equatorial ionospheric scintillations (de La Beaujardière et al., 2004) and has been collecting valuable data since 2008. The ion densities and compositions have been used previously as a constraint on empirical models such as the International Reference Ionosphere (Klenzing et al., 2011b, 2013). This study uses the topside density climatology derived from C/NOFS near the dip equator in the Pacific sector for the comparison with the SAMI2 results. As the perigee of C/NOFS is above the height of the F peak during the solar minimum, F3/C radio occultation data is also employed to determine the height and density of the peak.

\section{SAMI2 as a computational engine}

SAMI2 (Sami2 is Another Model of the Ionosphere) is a first principles low-latitude ionospheric model (Huba et al., 2000). It treats the dynamical and chemical evolution of the seven major ion species and electrons at altitudes starting at $90 \mathrm{~km}$. SAMI 2 provides densities, field-aligned drifts, and temperatures for each of the charged particle species as part of the standard output. These ionospheric characteristics are computed by solving the continuity and momentum equations for each of the ion species as well as for electrons. Thermal balance equations are also computed for $\mathrm{H}^{+}, \mathrm{He}^{+}$, $\mathrm{O}^{+}$, and the electrons. The terrestrial magnetic field is approximated by an IGRF-like dipole field, while the solar input, the neutral atmosphere, and the remaining ionospheric electrodynamics are specified using several empirical models that are described in detail in Sects. 2.1-2.4 and listed in Table 1. A sample of the ionosphere generated by SAMI2 for the afternoon is shown in Fig. 1.

Since SAMI2 accesses each of these supporting models in a modular fashion, it is relatively straightforward to alter the different physical processes governed by each model and evaluate the ionosphere produced by those changes. Table 1 includes a list of proposed changes to the supporting models meant to improve the performance of SAMI2 during an extreme solar minimum. In the following work, the result of each change is evaluated individually and accumulatively to determine the influence of each physical process on the ionosphere.

\subsection{MSIS}

The NRLMSISE-00 model (sometimes simply referred to as MSIS) provides the neutral density, composition, and temperature profiles for the background atmosphere (Picone et al., 2002). Previous studies (e.g., Emmert et al., 2010) have identified that during the extreme solar minimum the neutral mass density is significantly contracted, bringing the validity of the MSIS atmosphere into question under these conditions. To assess the ionospheric changes introduced by a contracted ionosphere, scaling factors were obtained by fitting the thermospheric mass density anomalies to measurements obtained by satellite drag calculations. Preliminary scaling values for the exospheric temperature $\left(T_{\infty_{\text {scl }}}=0.9603\right)$, neutral oxygen $\left(\mathrm{O}_{\mathrm{scl}}=0.7979\right)$, and other neutral species $\left(n_{x_{\mathrm{scl}}}=0.9697\right)$ are provided by Emmert and Siefring (private communication). This is consistent with a reduced dissociation of $\mathrm{O}_{2}$ due to reduced EUV irradiance.

\subsection{EUVAC}

The EUVAC model (Richards et al., 1994) provides EUV fluxes in 37 wavelength bins between 5 and $105 \mathrm{~nm}$ based on the solar radio flux at $10.7 \mathrm{~cm}\left(F_{10.7}\right)$. In SAMI2, the EUV fluxes are used to calculate the daytime production rates. For this study, we compare both the nominal output of EUVAC and a modified version where all EUV wavelengths are reduced by $15 \%$. This is based on the proposed reduction in EUV based on the MgII core-to-wing ratio from Solomon et al. (2011).

\subsection{ExB drifts}

The $\boldsymbol{E} \times \boldsymbol{B}$ drifts in the low-latitude ionosphere have been well-understood as a function of solar activity (e.g., Scherliess and Fejer, 1999). However, recent data from the 
Table 1. The empirical models used to drive the physics in SAMI2 and the changes applied for extreme solar minimum.

\begin{tabular}{lll}
\hline Model & Provides & Change Applied \\
\hline NRLMSISE-00 (Picone et al., 2002) & $N_{n}, T_{n}$ & Scalars from Emmert and Siefring \\
EUVAC (Richards et al., 1994) & Daytime photoionization rates & Reduce EUV by 15\% \\
$\boldsymbol{E} \times \boldsymbol{B}$ (Scherliess and Fejer, 1999) & vertical $\boldsymbol{E} \times \boldsymbol{B}$ drifts & Drift climatology from VEFI \\
HWM-07 (Drob et al., 2008) & horizontal winds & Sensitivity Study (see Section 5.1) \\
\hline
\end{tabular}

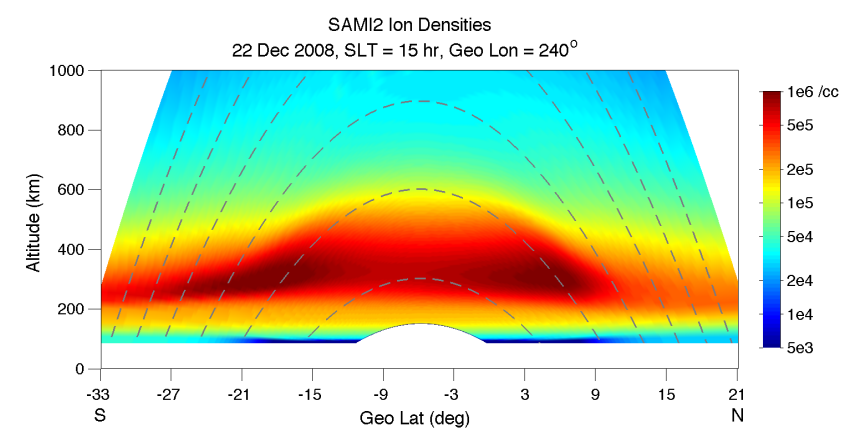

Fig. 1. The afternoon ion densities as predicted by SAMI2 for a two-dimensional stack of geomagnetic field lines near 240 degrees geographic longitude. The dashed lines represent field lines every $300 \mathrm{~km}$.

Vector Electric Field Instrument (VEFI) on C/NOFS during 2008 and 2009 have shown a number of surprising results, including downward drifts during the afternoon and a weak or non-existent pre-reversal enhancement (Pfaff et al., 2010). The Pacific sector is chosen for this study as there is a significant discrepancy in the direction of the observed drifts and the empirical models for low solar activity. This is illustrated in Fig. 2, where the median VEFI meridional $\boldsymbol{E} \times \boldsymbol{B}$ drifts are plotted along with the Fejer-Scherliess model (which drives the nominal SAMI2 runs). In general, the VEFI absolute accuracy during the early years of the C/NOFS program (2008-2010) is approximately $0.5 \mathrm{mV} \mathrm{m}^{-1}\left(15-20 \mathrm{~m} \mathrm{~s}^{-1}\right)$. However, the zonal electric field component (meridional drift component) is less reliable near the morning and sunset periods. The vertical bars on the data represent the upper and lower quartiles of the drifts during this period While the magnitude of the absolute accuracy is commensurate with the expected day-to-day drift variability, the median drift morphology with respect to local time for the 91 days of data in Fig. 2 provides valuable insight into the behavior of the ionosphere. Note that the median drifts begin moving downward in the early afternoon, whereas the modeled drifts do not move the plasma downward until 20 SLT. Additionally, while there is a local maxima in the median drift near sunset, the net drift is downward during this period and it cannot truly be called a pre-reversal enhancement. The median VEFI $\boldsymbol{E} \times \boldsymbol{B}$ drifts are modeled as a Fourier series (shown in red) to input into SAMI2 in place of the Fejer-Scherliess model. The drifts are modeled as

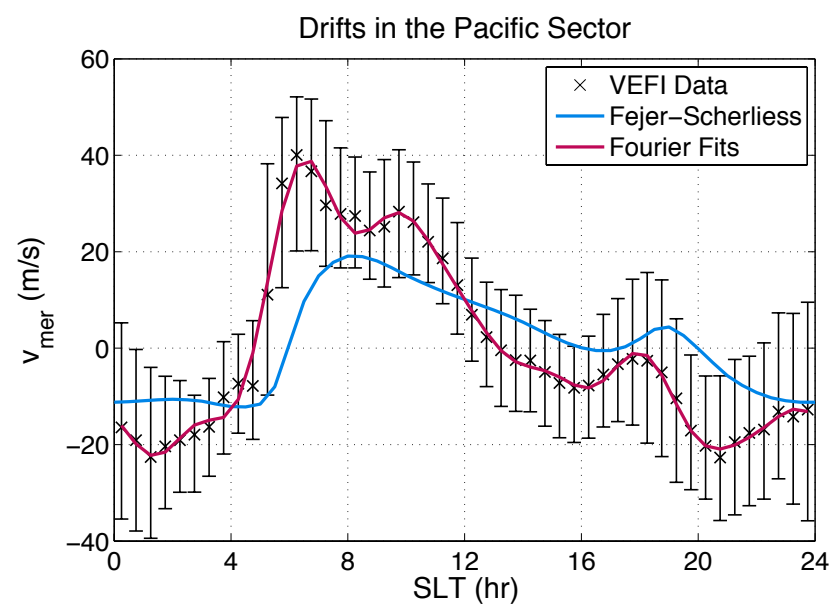

Fig. 2. The median vertical $\boldsymbol{E} \times \boldsymbol{B}$ drifts as measured by VEFI compared with the Fejer-Scherliess model for low solar activity. The vertical bars represent the upper and lower quartiles of the data.

$\boldsymbol{E} \times \boldsymbol{B}(t)=\sum_{k=1}^{8} a_{k} \cos \left(\frac{2 k \pi t}{T}\right)+b_{k} \sin \left(\frac{2 k \pi t}{T}\right)$,

where $t$ represents solar local time, and the period $T$ is 24 . Note that the average meridional drift over time is zero because the constant offset term $a_{0}$ is neglected. Since SAMI2 is a two-dimensional model that extends both parallel to $\boldsymbol{B}$ and perpendicular to $\boldsymbol{B}$ in the meridonal direction, the zonal drifts are not used in this study.

\subsection{HWM}

The Horizontal Wind Model (HWM) is used to provide the neutral winds $\left(u_{\mathrm{n}}\right)$ based on a large statistical database of wind data from satellites, sounding rockets, interferometers, and radar (Hedin et al., 1991, 1996; Drob et al., 2008). The latest version (HWM-07) represents a significant improvement over the previous model bundled with the SAMI2 code (HMW-93) due to the 50-fold increase in the number of observations incorporated by the empirical model. Additionally, the dependence on $F_{10.7}$, which was noted to be slight in the original model, has been removed in the latest version. While some problems have been noted with the equinoctial seasons, this does not affect the solsticial seasons. It is 


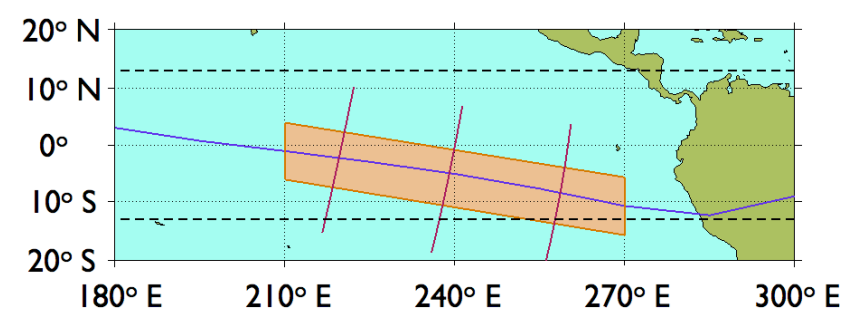

Fig. 3. The test region over the Pacific Sector. The red lines represent the three discrete SAMI2 runs. CINDI data throughout the orange box is averaged together to provide the average densities for the SAMI 2 constraints.

expected that the change in $\boldsymbol{E} \times \boldsymbol{B}$ drifts would coincide with a change in the winds, but the lack of neutral wind measurements during the December solstice of 2008 makes it impossible to implement the same type of data-based comparison performed with the $\boldsymbol{E} \times \boldsymbol{B}$ drifts. Instead, the two most recent versions of HWM (93 and 07) are used to explore the influence of changing neutral winds on the ionosphere in Sect. 5.1.

\section{Model-data comparison}

Figure 3 shows the Pacific sector with the test region highlighted in orange. The test region includes longitudes between $210^{\circ}$ and $270^{\circ} \mathrm{E}$ and magnetic latitudes within five degrees of the magnetic dip equator. The dashed lines represent the orbital limits of the C/NOFS satellite. Note that there is a small region of the test area that C/NOFS cannot reach; however, this is trivial. For both data sets, 91 days of data centered about the December solstice (6 November 20084 February 2009) is used to compute the average topside density, and the median $\mathrm{F}$ peak density $(\mathrm{Nm} \mathrm{F} 2)$ and height ( $h m \mathrm{~F} 2$ ).

Because the dataset covers a finite range of longitudes and days, multiple runs of SAMI2 are combined for comparison to the data. Three representative longitudes $\left(220^{\circ}, 240^{\circ}\right.$, and $260^{\circ}$ ) are chosen, and each run is performed for five different days evenly spaced through the 91 day season (specifically, days 316,336 , and 356 of 2008 and days 10 and 30 of 2009). The SAMI2 values for total ion density and component ion density are then averaged together as a function of local time, altitude, and magnetic latitude using the same criteria as the $\mathrm{C} / \mathrm{NOFS}$ data. The peak density $(N m \mathrm{~F} 2)$ and height $(h m \mathrm{~F} 2)$ are identified at the dip equator for each individual run, and the median of these values is reported for each case study.

\subsection{C/NOFS data}

The C/NOFS satellite was launched in April 2008 into a $13^{\circ}$ inclination orbit with perigee near $400 \mathrm{~km}$ and apogee near $860 \mathrm{~km}$. This elliptical orbit allows for a sampling of ion density over multiple $\mathrm{O}^{+}$scale heights of the topside equatorial ionosphere. The satellite's perigee precesses through all solar local times approximately every 65 days, allowing for the reconstruction of average topside density profiles as a function of altitude, dip latitude, and local time (Klenzing et al., 2011b).

C/NOFS is equipped with multiple instrument suites designed to study the ion and neutral populations and their effect on the propagation of communication signals (de La Beaujardière et al., 2004). Of interest to this study is the ion density (which is equal to the electron density for a quasi-neutral plasma) and composition, which are provided by the Retarding Potential Analyzer (RPA) from the Coupled Ion-Neutral Dynamics Investigation (CINDI) suite of instruments. The RPA technique is a well-established in situ method of sampling ion density, temperature, and composition (Heelis and Hanson, 1998). The composition measurements in this study are discussed in terms of $\mathrm{H}^{+}$and $\mathrm{O}^{+}$, which are the two dominant species in the topside ionosphere.

The topside ion densities are reconstructed in a similar fashion to the procedure outlined in Klenzing et al. (2011b). In summary, a Savitsky-Golay filter (Savitsky and Golay, 1964) is used on the CINDI data to remove small-scale plasma density irregularities. Larger scale irregularities are removed through use of the method of Su et al. (2006), which uses a density fluctuation parameter $\left(\sigma_{\mathrm{p}}\right)$ to determine the level of fluctuation around a $10 \mathrm{~s}$ segment of linearly detrended ion density data. This dimensionless parameter is defined as:

$$
\begin{aligned}
& \sigma_{\mathrm{p}}=\frac{1}{L}\left[\frac{1}{10} \sum_{j=1}^{10}\left[\log \left(N_{j}\right)-\log \left(N_{0 j}\right)\right]^{2}\right]^{1 / 2}, \\
& L=\frac{1}{10} \sum_{j=1}^{10} \log \left(N_{0 j}\right),
\end{aligned}
$$

where $N_{j}$ is the density data (at 1 sample s $^{-1}$ ) and $N_{0 j}$ is a linear fit to the $10 \mathrm{~s}$ group of data. Values of $\sigma_{\mathrm{p}}$ greater than $2 \times 10^{-4}$ are eliminated from the climatologies. (This threshold was chosen through visual inspection of the data.) Additionally, only geomagnetically quiet times where $\mathrm{Kp} \leq 3$ for the preceding $24 \mathrm{~h}$ are used in the averages. For this study, we only consider geographic longitudes in the Pacific sector (between $210^{\circ}$ and $270^{\circ} \mathrm{E}$ ). The data are averaged over local time (with a bin width of $2.5 \mathrm{~h}$ ) and altitude $(50 \mathrm{~km})$. Only data near the geomagnetic dip equator (within 5 degrees) are used in the averages. (Note that these criteria are also applied to the VEFI $\boldsymbol{E} \times \boldsymbol{B}$ climatology.)

\section{$3.2 \quad F 3 / C$ data}

The Formosa Satellite-3/Constellation Observing System for Meteorology, Ionosphere, and Climate (FORMOSAT3/COSMIC or $\mathrm{F} 3 / \mathrm{C}$ ) mission provides vertical profiles of 


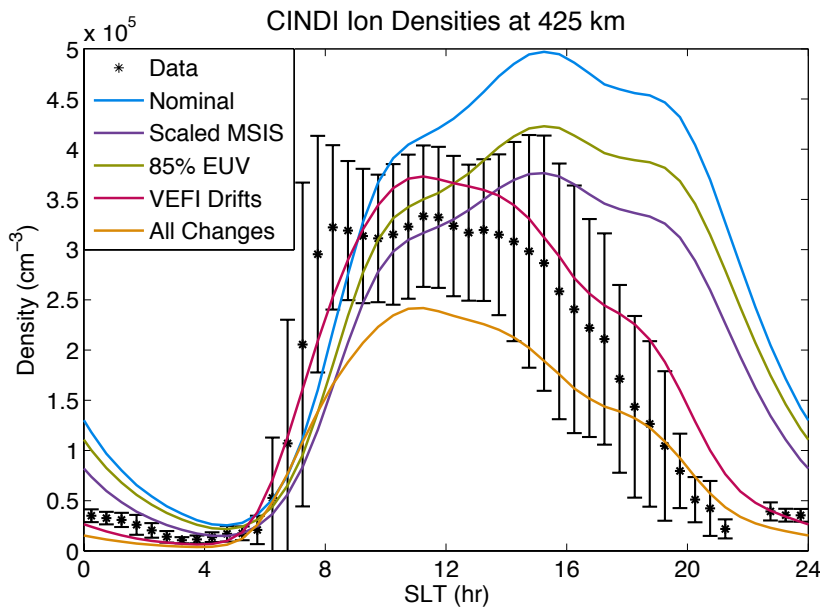

Fig. 4. The average ion density as measured by CINDI at $425 \mathrm{~km}$ altitude as a function of local time. The colored lines represent the predicted densities based on the different SAMI2 runs. The vertical bars represent standard deviations of the dataset, which largely consist of the day-to-day variability of the ionosphere.

several atmospheric and ionospheric quantities in fulfillment of its primary scientific goal (Cheng et al., 2006). The F3/C constellation consists of six microsatellites that orbit at an altitude of $800 \mathrm{~km}$. These microsatellites were launched on 15 April 2006, and over the subsequent 16 months spread out to achieve a longitudinal separation of $30^{\circ}$. Each microsatellite has an inclination of $72^{\circ}$, an orbital period of $100 \mathrm{~min}$, and is equipped with a Global Positioning System (GPS) Occultation eXperiment (GOX) payload. The GOX payload is used to obtain electron density profiles spanning altitudes between $90-800 \mathrm{~km}$.

The electron density profiles used in this study are publicly available in the post-processed ion profile files provided by the COSMIC Data Analysis and Archival Center (CDAAC). Extracting the location and magnitude of the electron density peak provides the height and density of the $\mathrm{F} 2$ peak $(h m \mathrm{~F} 2$ and $N m \mathrm{~F} 2$, respectively). To exclude any instances the altitude of the peak electron density cannot physically represent the $h m \mathrm{~F} 2$, only peak altitudes greater than $120 \mathrm{~km}$ were used. This requirement is less stringent than those used in other studies (e.g., Liu et al., 2011; Lin et al., 2007), but the inclusion of questionable profiles was shown by Liu et al. (2011) to have little influence over average results. Yue et al. (2010) showed that the F3/C $h m F 2$ error was between 7.4 and $8.9 \mathrm{~km}$ globally (for day and nighttimes, respectively), while the $N m \mathrm{~F} 2$ error was between $1.4 \times 10^{11}$ and $3.2 \times 10^{10} \mathrm{~m}^{-3}$ (for day and nighttimes, respectively). These errors are larger at low latitudes (where the assumption of spherical symmetry is violated) and at twilight (when large horizontal electron density gradients may be seen across the solar terminator). The F3/C data is analyzed in the same test region as the C/NOFS data (Fig. 3).

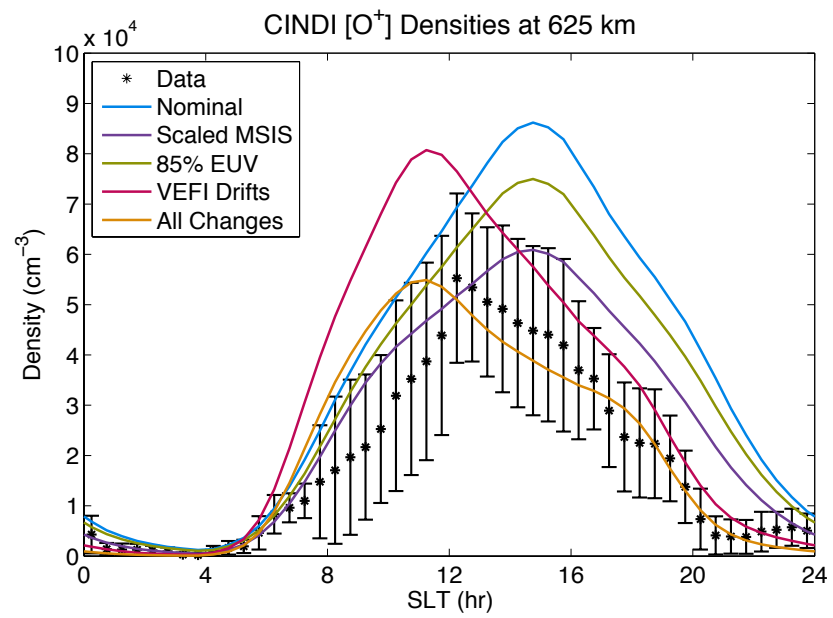

Fig. 5. The average $\mathrm{O}^{+}$density as measured by CINDI at $625 \mathrm{~km}$ altitude as a function of local time. The colored lines represent the predicted densities based on the different SAMI2 runs. The vertical bars represent standard deviations.

\section{Results}

The results of the study are presented in Figs. 4-8. In all cases, the data is presented as a black dashed line with vertical bars (representing mean and standard deviation for the CINDI density data, and medians and quartiles for the F3/C GOX data). These vertical bars reflect the day-to-day variability of the ionosphere during this 91 day season rather than an error in the measurement. The five solid lines represent the five model runs: a nominal run where no modifications are made (blue), a run where the MSIS model is scaled (purple), a run where the EUVAC model is reduced (green), a run where the VEFI climatology replaces the $\boldsymbol{E} \times \boldsymbol{B}$ model (red), and a run where all three of these changes are implemented (orange).

Figure 4 shows the average topside density between 400 and $450 \mathrm{~km}$ as measured by CINDI. Scaling the MSIS model and reducing EUV both reduce the modeled density, but do not result in a change in morphology as a function of local time. The model run with a scaled MSIS produces a larger effect than the run with a reduced EUV. Note that only when the VEFI drifts are incorporated does the modeled topside density become consistent with the data in the afternoon/nightside regime. In fact, the nominal SAMI2 simulation overestimates the density at this height by up to a factor of 12 (with the greatest overestimate near 21 SLT).

Figure 5 shows the average density of $\mathrm{O}^{+}$between 600 and $650 \mathrm{~km}$ as measured by CINDI. This range of altitudes were chosen as this is near the daytime transition height between $\mathrm{O}^{+}$and $\mathrm{H}^{+}$(e.g., Klenzing et al., 2011b). Again, altering MSIS or EUV produces no change in morphology. The best comparison in this case incorporates all three proposed changes. 


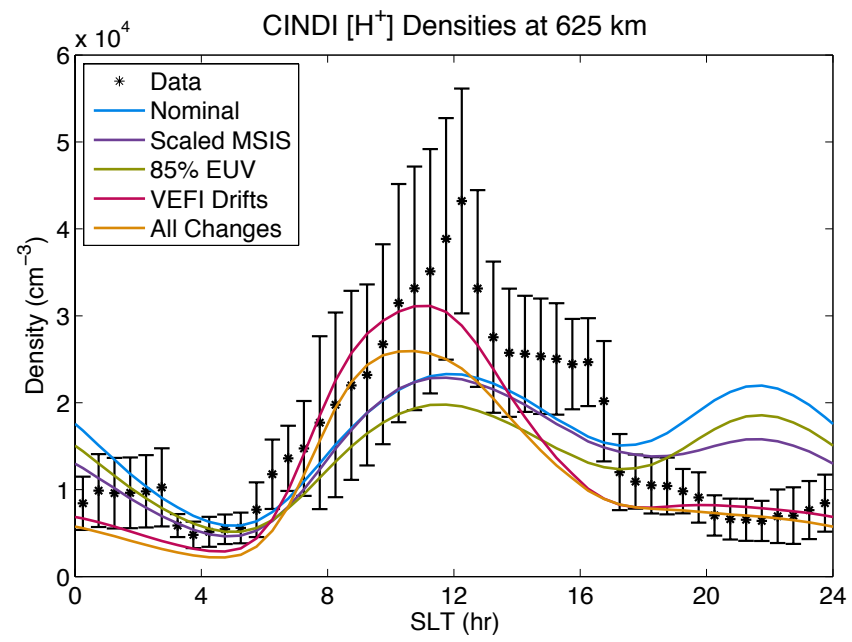

Fig. 6. The average $\mathrm{H}^{+}$density as measured by CINDI at $625 \mathrm{~km}$ altitude as a function of local time. The colored lines represent the predicted densities based on the different SAMI2 runs. The vertical bars represent standard deviations.

Figure 6 shows the average density of $\mathrm{H}^{+}$in the same range as Fig. 5. Again, the two cases incorporating VEFI drifts match the data better than the three cases using FejerScherliess. Most notably, the daytime concentration of $\mathrm{H}^{+}$ is raised and the nightside concentrations are significantly lowered, removing the large lobe of $\left[\mathrm{H}^{+}\right]$predicted by the nominal SAMI2 run. Note that this lobe of $\left[\mathrm{H}^{+}\right]$is also predicted by the IRI-2007 model for a typical solar minimum and appears in the CINDI data during 2010 (Klenzing et al., 2011b).

Figure 7 shows the median $N m \mathrm{~F} 2$ values near the dip equator. Again, no changes in morphology are evident from altering the MSIS or EUVAC models. Incorporating the VEFI drifts produces a curve more consistent with the data, but using all three changes simultaneously pushes $N m \mathrm{~F} 2$ to below the first quartile during the dayside.

Figure 8 shows the median height of the ionosphere $(h m \mathrm{~F} 2)$ near the dip equator for the Pacific sector. In this case, changing the MSIS and EUVAC models produce little to no change in the height of the $\mathrm{F}$ layer. However, incorporating the VEFI drifts reduces the post-sunset height by nearly $80 \mathrm{~km}$, matching the $\mathrm{F} 3 / \mathrm{C}$ data well.

Table 2 shows the RMS errors for each of Figs. $4-8$ as calculated using

$\mathrm{RMS}=\sqrt{\frac{1}{48} \sum_{j=1}^{48}\left(\mathcal{D}_{j}-\mathcal{M}_{j}\right)^{2}}$,

where $\mathcal{D}_{j}$ is the data point for the $j$ th value of SLT (reported every $0.5 \mathrm{~h}$ ), and $\mathcal{M}_{j}$ is the associated model value from a given SAMI2 run. It is clear from Figs. 4-8 and Table 2 that while changing the neutral background and the

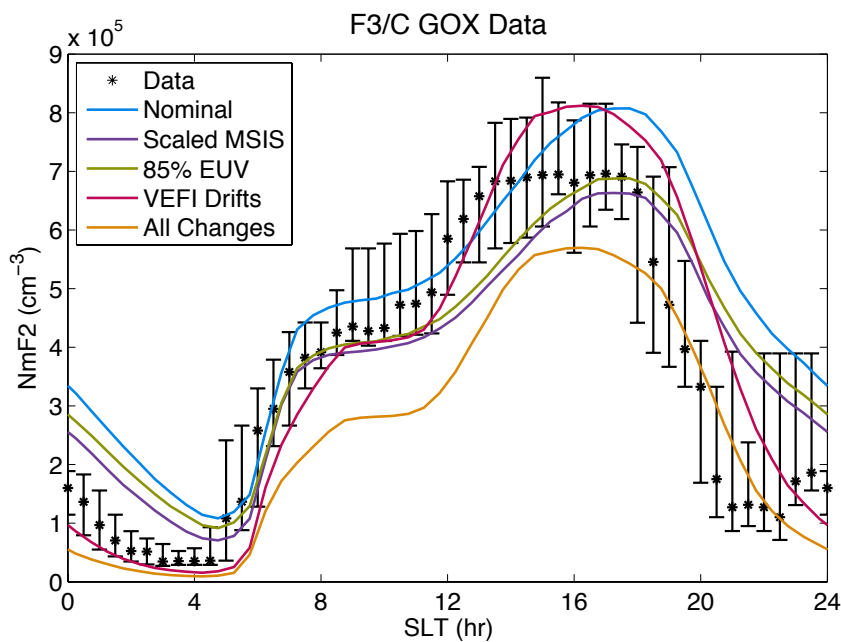

Fig. 7. The median $N m \mathrm{~F} 2$ values derived from F3/C, with the vertical bars representing the upper and lower quartiles. The modeled results are the same as Fig. 4.

photoionization rates push all five metrics in the correct direction, significant progress is only made when the vertical ion drifts are modeled based on the experimental data.

\section{Discussion}

This case study in the Pacific sector is likely to be an extreme case, based on analysis of the drift climatology as a function of longitude (see Pfaff et al., 2010, for a complete description). The downward motion of the afternoon ionosphere in this sector observed with VEFI is consistent with the observed density and composition from CINDI and the profiles from F3/C. The lowering of the nighttime $\mathrm{F}$ peak by $80 \mathrm{~km}$ is likely to produce significantly different dynamics on the topside ionosphere. In particular, the concentration of $\mathrm{H}^{+}$here is largely governed by charge exchange with $\mathrm{O}^{+}$ (Rishbeth and Garriott, 1969), which can be approximated to first order by the expression

$\left[\mathrm{H}^{+}\right]=\frac{9}{8} \frac{[\mathrm{H}]}{[\mathrm{O}]}\left[\mathrm{O}^{+}\right]$.

When the ionosphere is lowered, the ratio of neutral $[\mathrm{H}]$ to $[\mathrm{O}]$ is decreased, and the large lobe of $\mathrm{H}^{+}$predicted on the nightside ionosphere goes away. However, several other effects should be noted that influence the resultant ion distributions.

\subsection{Sensitivity to winds}

Because of the lack of neutral wind data during the deepest part of the minimum, all of the case studies discussed so far have used identical winds from the HWM-07 model. In order to understand the potential effects of the winds in 
Table 2. RMS Deviations from data.

\begin{tabular}{lccccc}
\hline SAMI2 run & $N_{i}$ & {$\left[\mathrm{O}^{+}\right]$} & {$\left[\mathrm{H}^{+}\right]$} & $N m \mathrm{~F} 2$ & $h m \mathrm{~F} 2$ \\
\hline Nominal & $1.76 \times 10^{5} \mathrm{~cm}^{-3}$ & $2.36 \times 10^{4} \mathrm{~cm}^{-3}$ & $8.39 \times 10^{3} \mathrm{~cm}^{-3}$ & $1.66 \times 10^{5} \mathrm{~cm}^{-3}$ & $37.6 \mathrm{~km}$ \\
Scaled MSIS & $1.10 \times 10^{5} \mathrm{~cm}^{-3}$ & $1.08 \times 10^{4} \mathrm{~cm}^{-3}$ & $6.81 \times 10^{3} \mathrm{~cm}^{-3}$ & $1.18 \times 10^{5} \mathrm{~cm}^{-3}$ & $32.9 \mathrm{~km}$ \\
85\% EUV & $1.37 \times 10^{5} \mathrm{~cm}^{-3}$ & $1.77 \times 10^{4} \mathrm{~cm}^{-3}$ & $8.70 \times 10^{3} \mathrm{~cm}^{-3}$ & $1.29 \times 10^{5} \mathrm{~cm}^{-3}$ & $37.5 \mathrm{~km}$ \\
VEFI Drifts & $4.30 \times 10^{4} \mathrm{~cm}^{-3}$ & $1.83 \times 10^{4} \mathrm{~cm}^{-3}$ & $4.98 \times 10^{3} \mathrm{~cm}^{-3}$ & $1.05 \times 10^{5} \mathrm{~cm}^{-3}$ & $16.6 \mathrm{~km}$ \\
All Changes & $6.73 \times 10^{4} \mathrm{~cm}^{-3}$ & $8.38 \times 10^{3} \mathrm{~cm}^{-3}$ & $6.38 \times 10^{3} \mathrm{~cm}^{-3}$ & $1.26 \times 10^{5} \mathrm{~cm}^{-3}$ & $16.4 \mathrm{~km}$ \\
HWM-93 + Nominal & $1.23 \times 10^{5} \mathrm{~cm}^{-3}$ & $1.53 \times 10^{4} \mathrm{~cm}^{-3}$ & $3.55 \times 10^{3} \mathrm{~cm}^{-3}$ & $1.12 \times 10^{5} \mathrm{~cm}^{-3}$ & $36.1 \mathrm{~km}$ \\
HWM-93 + All Changes & $7.97 \times 10^{4} \mathrm{~cm}^{-3}$ & $8.49 \times 10^{3} \mathrm{~cm}^{-3}$ & $4.94 \times 10^{3} \mathrm{~cm}^{-3}$ & $1.39 \times 10^{5} \mathrm{~cm}^{-3}$ & $18.3 \mathrm{~km}$ \\
\hline
\end{tabular}

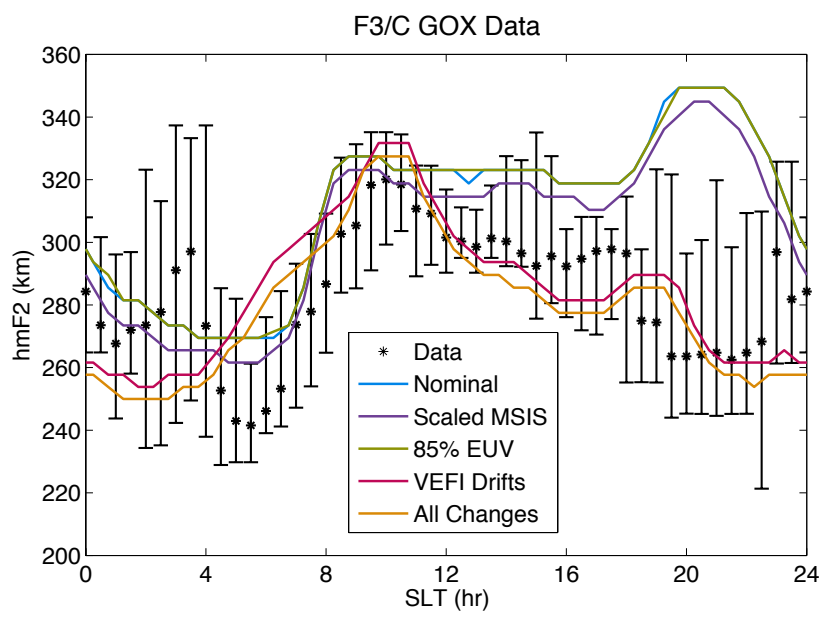

Fig. 8. The median $h m \mathrm{~F} 2$ values derived from F3/C, with the vertical bars representing the upper and lower quartiles. The modeled results are the same as Fig. 4 .

the SAMI2 model, a brief sensitivity study was conducted, which is shown in Figs. 9-10. Here two different assumptions for the winds employed, as depicted in Fig. 9. These include HWM-07 (solid) and HWM-93 (dashed, Hedin et al., 1991, 1996). Both models output a northward wind as expected, but morphology as a function of local time varies. With the exception of changing the wind models, each case is conducted and averaged as before. The five metrics from Figs. 4-8 are shown in Fig. 10 as before. Note that the solid colored lines are identical to the Nominal (blue) and All Changes (orange) SAMI2 runs using HWM-07 from the previous case studies, whereas the dashed colored lines represent the new cases using HWM-93.

The change in the winds produces a significant change in the topside ionosphere for the nominal run. The most notable change is the reduction of the large lobe of $\left[\mathrm{H}^{+}\right]$on the nightside in panel $\mathrm{d}$, though the modeled nightside $\left[\mathrm{H}^{+}\right]$ still is more than one standard deviation above the measured mean. However, the height of the post-sunset F peak is relatively unchanged, particularly after 21 SLT. An HWM-93 run where only MSIS is scaled produced changes in magnitude but not morphology as before (not shown). When the $\boldsymbol{E} \times \boldsymbol{B}$

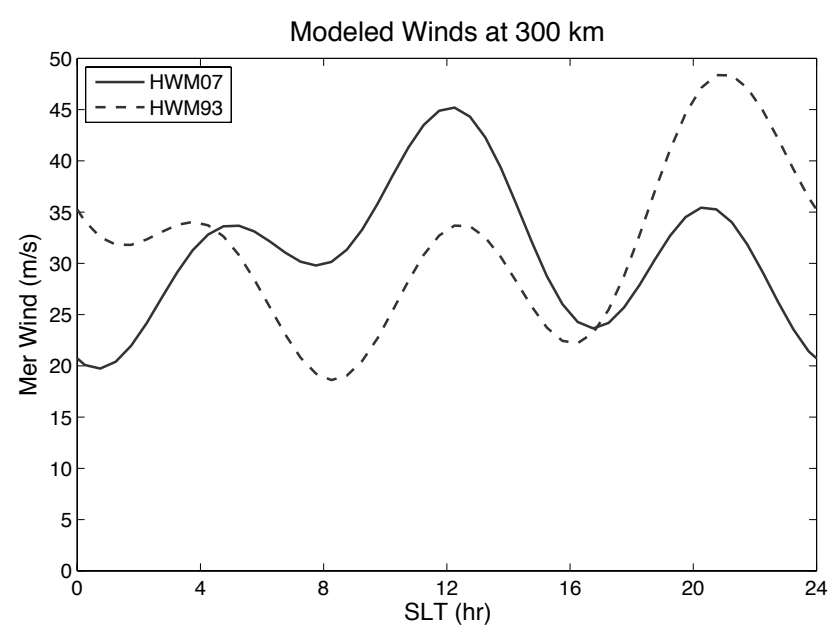

Fig. 9. The equatorial neutral winds at $300 \mathrm{~km}$ and $240^{\circ}$ E predicted by HWM-07 (solid) and HWM-93 (dashed).

drifts are included in the simulation, the effect of changing the wind model produces much smaller changes in the resulting metrics (see the orange solid and dashed lines in Fig. 10). Additionally, when the All Changes + HWM-93 case study is compared to the HWM- 07 version in Table 2, only one metric sees an improvement in the RMS deviation from data $\left(\left[\mathrm{H}^{+}\right]\right)$. The other four metrics see a slight increase in RMS deviations ranging from $1 \%$ to $18 \%$ over the corresponding HWM-07 case study.

It is important to understand why the choice of wind model appears to be less important once drifts are included. The winds affect the topside ionosphere both through local collisions and through plasma diffusion, which (depending on the local time) is primarily driven by the winds in the lower thermosphere that raise or lower the ion density peak. Since the changes in the topside ionosphere between the HWM-07 and HWM-93 runs are smaller when the $\boldsymbol{E} \times \boldsymbol{B}$ drifts are included, it can be concluded that the ionospheric changes introduced by the winds are driven by the lower thermospheric winds that drive the field-aligned plasma pressure gradient rather than the local winds. Such plasma pressure gradients have been shown to correlate with the transport of ionized oxygen across the geomagnetic equator (Burrell and Heelis, 

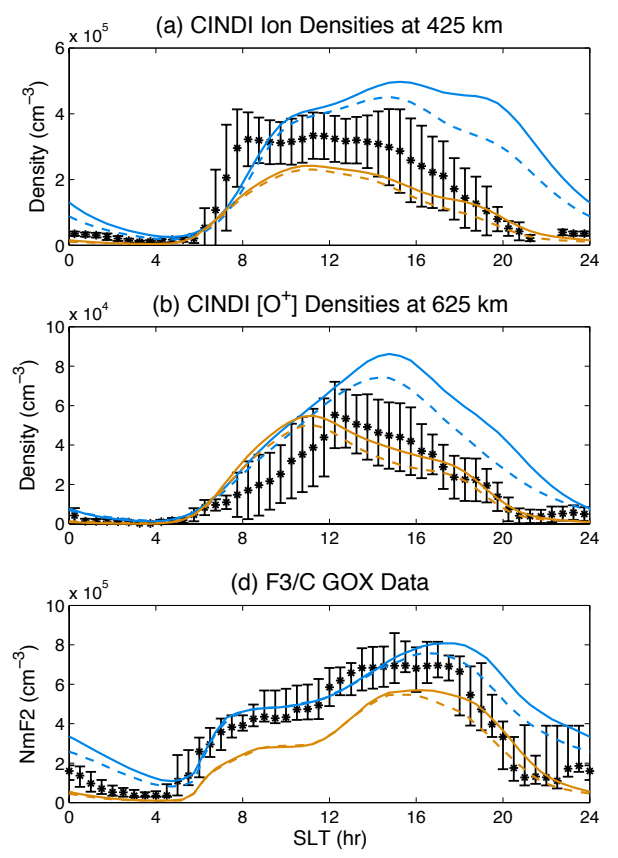
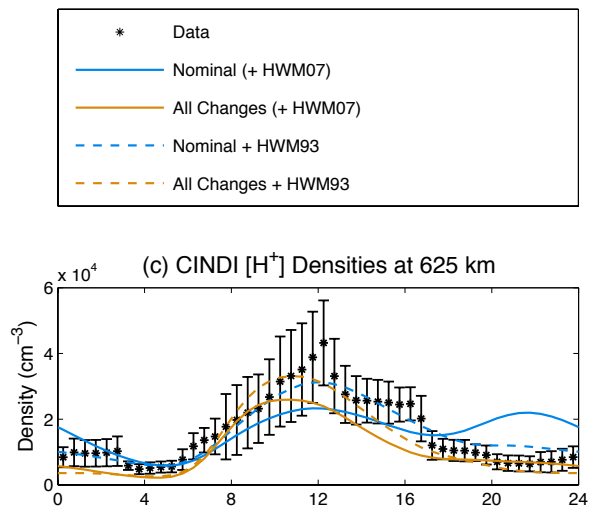

(e) F3/C GOX Data

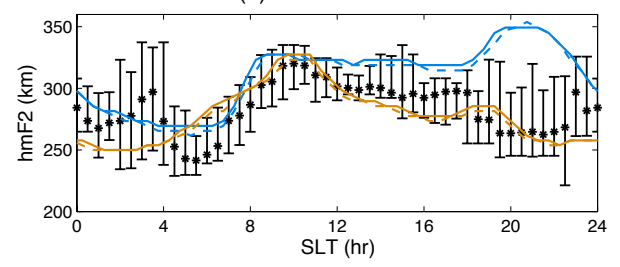

Fig. 10. A sensitivity study for the neutral winds compared to the five metrics used above in Figs. 4-8. The solids lines indicate simulations using the HWM-07 model and are identical to the respective lines in the preceding figures. The dashed lines use the HWM-93 model to demonstrate the sensitivity to the wind morphologies shown in Fig. 9.

2012), which influences both the ion density and composition in the topside ionosphere (West and Heelis, 1996; West et al., 1997). Decoupling the collisional and electrodynamical influence from the field-aligned plasma pressure gradient, which causes diffusive motion, is an important next step to take to further our understanding of the ionospheric electrodynamics during extremely low solar activity.

\subsection{Tropospheric forcing}

Tidal effects in the troposphere are expected to modify the neutral profile as a function of longitude, which in turn will modify the resultant ionosphere (see England, 2012, for an in-depth review). There is evidence that during the recent solar minimum, the effects of the tides on the ionosphere are stronger, as manifested in the C/NOFS plasma density data as a function of longitude (Huang et al., 2012). Tidal effects are partially accounted for here, as these longitudinal variations are very evident in the VEFI $\boldsymbol{E} \times \boldsymbol{B}$ data (Pfaff et al., 2010), as well as the MSIS empirical model. While there may be additional modifications to the neutral density and composition profiles required during 2008 and 2009 due to low solar activity, these effects are likely to be small relative to the changes already implemented here. There may be an additional variation in the neutral winds, as HWM-07 does not include the effects of non-migrating tides (Drob et al., 2008). However, these effects have been included using the TIME-GCM model (Roble and Ridley, 1994) and can be used in SAMI2 in future studies to assess the effects of tidal signatures and longitudinal dependence. In the present study, only one longitudinal region is examined. Future work will look at multiple longitudes to understand how well the SAMI2 model represents tidal signatures with the changes implemented here.

\section{Summary and conclusions}

The extreme solar minimum between solar cycles 23 and 24 is a unique case to test the limits of empirical and physical models. Previously discussed alterations to the NRLMSISE00, EUVAC, and Fejer-Scherliess models have been incorporated into the SAMI2 physical model of the equatorial ionosphere. Ionospheric data in the Pacific sector from both the C/NOFS satellite and the F3/C constellation during the December solstice of 2008 are compared to the modeling results.

The conclusions are:

1. In all cases, incorporating the VEFI drift climatology significantly improve the model results when compared to both the C/NOFS density data and the F3/C GOX data. Changing the MSIS and EUVAC models produced changes in magnitude, but not morphology.

2. Determining the "best" combination of changes to use overall is difficult. In some cases (such as $\left[\mathrm{O}^{+}\right]$), modifying all three models produces the best comparison to the data. In other cases (such as $N m \mathrm{~F} 2$ ), only altering 
the drifts produces the best comparison. This suggests that required changes to the empirical models are more complicated than the rather simple changes evaluated here. In particular, it is clear that the neutral winds can play an additional role in modulating the resultant topside ionospheric density and composition, but the lack of wind measurements makes it difficult to know whether the "correct" winds are included in the model.

3. In the Pacific sector, the nighttime $h m \mathrm{~F} 2$ as measured by $\mathrm{F} 3 / \mathrm{C}$ is about $80 \mathrm{~km}$ lower than predicted by a nominal SAMI2 run. Incorporating the VEFI drifts into SAMI2 produces nighttime $F$ region heights consistent with the data in this region. Changing the wind model did not affect the resultant $h m \mathrm{~F} 2$, though the changes in the $h m \mathrm{~F} 2$ and $N m \mathrm{~F} 2$ off the geomagnetic equator are likely to be larger since the neutral winds were shown to play a role in modulating the topside ionosphere.

4. This drop in altitude of the F peak is consistent with the observed decreased density at fixed altitudes in the topside ionosphere. At $425 \mathrm{~km}$, the nominal SAMI 2 run overestimates density by up to a factor of 12 after sunset. Incorporating the VEFI drifts into SAMI2 significantly improves the topside estimation of the nighttime ionosphere density and composition.

Future work on the extreme solar minimum will look at longitudinal and seasonal variations, as well the effects of the day-to-day variability of the ionosphere. Additionally, these results are important for the modeling of electromagnetic phenomena that rely on the shape of the ionospheric profile, including Schumann resonances, which occur in the cavity between the surface of the earth and the bottom side ionosphere (Simões et al., 2011), and the Ionospheric Alfvén Resonator (IAR), which occurs in the F-layer itself (Simões et al., 2012). Both of these phenomena have been observed by VEFI during the extreme solar minimum and are under consideration as possible metrics for future studies.

Acknowledgements. The Communication/Navigation Outage Forecast System (C/NOFS) mission, conceived and developed by the Air Force Research Laboratory (AFRL), is sponsored and executed by the USAF Space Test Program. Thanks to J. Emmert and C. Siefring for providing the MSIS scalars. The authors would like to thank the F3/C orbital operation team at the National Space Organization (NSPO) and the University Corporation for Atmospheric Research (UCAR) for their roles in obtaining and distributing the F3/C data. This work uses the SAMI2 ionosphere model written and developed by the Naval Research Laboratory.

Topical Editor F. Rodrigues thanks two anonymous referees for their help in evaluating this paper.

\section{References}

Araujo-Pradere, E. A., Redmon, R., Fedrizzi, M., Viereck, R., and Fuller-Rowell, T. J.: Some Characteristics of the Ionospheric Behavior During the Solar Cycle 23-24 Minimum, Solar Phys., 274, 439-456, doi:10.1007/s11207-011-9728-3, 2011.

Burrell, A. G. and Heelis, R. A.: The influence of hemispheric asymmetries on field-aligned ion drifts at the geomagnetic equator, Geophys. Res. Lett., 39, L19101, doi:10.1029/2012GL053637, 2012.

Candido, C. M. N., Batista, I. S., Becker-Guedes, F., Abdu, M. A., Sobral, J. H. A., and Takahashi, H.: Spread F occurrence over a southern anomaly crest location in Brazil during June solstice of solar minimum activity, J. Geophys. Res., 116, A06316, doi:10.1029/2010JA016374, 2011.

Cheng, C., Kuo, Y., Anthes, R., and Wu, L.: Satellite constellation monitors global and space weather, Eos T. Am. Geophys. Un., 87, p. 166, doi:10.1029/2006EO170003, 2006.

de La Beaujardière, $\mathrm{O}$. and the C/NOFS Definition Team: C/NOFS: a mission to forecast scintillations, J. Atmos. Sol.-Terr. Phys., 66, 1573, doi:10.1016/j.jastp.2004.07.030, 2004.

Deng, Y., Huang, Y., Solomon, S., Qian, L., Knipp, D., Weimer, D. R., and Wang, J.-S.: Anomalously low geomagnetic energy inputs during 2008 solar minimum, J. Geophys. Res., 117, A09307, doi:10.1029/2012JA018039, 2012.

Drob, D. P., Emmert, J. T., Crowley, G., Picone, J. M., Shepherd, G. G., Skinner, W., Hays, P., Niciejewski, R. J., Larsen, M., She, C. Y., Meriwether, J. W., Hernandez, G., Jarvis, M. J., Sipler, D. P., Tepley, C. A., O'Brien, M. S., Bowman, J. R., Wu, Q., Murayama, Y., Kawamura, S., Reid, I. M., and Vincent, R. A.: An empirical model of the Earth's horizontal wind fields: HWM07, J. Geophys. Res., 113, A12304, doi:10.1029/2008JA013668, 2008.

Emmert, J. T., Lean, J. L., and Picone, J. M.: Record-low thermospheric density during the 2008 solar minimum, Geophys. Res. Lett., 37, L12102, doi:10.1029/2010GL043671, 2010.

England, S. L.: A Review of the Effects of Non-migrating Atmospheric Tides on the Earth's Low-Latitude Ionosphere, Space Sci Rev., 168, 211-236, doi:10.1007/s11214-011-9842-4, 2012.

Haaser, R. A., Earle, G. D., Heelis, R. A., Coley, W. R., and Klenzing, J. H.: Low-latitude measurements of neutral thermospheric helium dominance near $400 \mathrm{~km}$ during extreme solar minimum, J. Geophys. Res., 115, A11318, doi:10.1029/2010JA015325, 2010.

Hedin, A. E., Biondi, M. A., Burnside, R. G., Hernandez, G., Johnson, R. M., Killeen, T. L., Mazaudier, C., Meriweather, J. W. Salah, J. E., Sica, R. J., Sith, R. W., Spencer, N. W., Wickwar, V. B., and Virdi, T. S.: Revised global model of thermophere winds using satellite and ground-based observations, J. Geophys. Res., 96, 7657-7688, 1991.

Hedin, A. E., Fleming, E. L., Manson, A. H., Schmidlin, F. J., Avery, S. K., Clark, R. R., Franke, S. J., Fraser, G. J., Tsuda, T., Vial, F., and Vincent, R. A.: Empirical wind model for the upper, middle and lower atmosphere, J. Atmos. Terr. Phys., 58, 1421-1447, 1996.

Heelis, R. A. and Hanson, W. B.: Measurements of thermal ion drift velocity and temperature using planar sensors, in: Measurement Techniques in Space Plasmas (Geophys. Monogr. Ser. Vol. 102), edited by: Pfaff, R. F., Borovsky, J. E., and Young, D. T., AGU, Washington, D.C., 61-71, 1998. 
Heelis, R. A., Coley, W. R., Burrell, A. G., Hairston, M. R., Earle, G. D., Perdue, M. D., Power, R. A., Harmon, L. L., Holt, B. J., and Lippincott, C. R.: Behavior of the $\mathrm{O}^{+} / \mathrm{H}^{+}$transition height during the extreme solar minimum of 2008, Geophys. Res. Lett., 36, L00C03, doi:10.1029/2009GL038652, 2009.

Huang, C. Y., Delay, S. H., Roddy, P. A., Sutton, E. K., and Stoneback, R.: Longitudinal structures in the equatorial ionosphere during deep solar minimum, J. Atmos. Sol.-Terr. Phys., 90-91, 156-163, 2012.

Huba, J. D., Joyce, G., and Fedder, J. A.: Sami2 is Another Model of the Ionosphere (SAMI2) - A new low-latitude ionosphere model, J. Geophys. Res., 105, 23035-23053, 2000.

Klenzing, J. H., Rowland, D. E., Pfaff, R. F., Le, G., Freudenreich, H., Haaser, R. A., Burrell, A. G., Stoneback, R. A. Coley, W. R., and Heelis, R. A.: Observations of low-latitude plasma density enhancements and their associated plasma drifts, J. Geophys. Res. 116, A09324, doi:10.1029/2011JA016711, 2011a.

Klenzing, J., Simões, F., Ivanov, S., Heelis, R. A., Bilitza, D., Pfaff, R., and Rowland, D.: Topside equatorial ionospheric density and composition during and after extreme solar minimum, J. Geophys. Res., 116, A12330, doi:10.1029/2011JA017213, 2011 b.

Klenzing, J., Simões, F., Ivanov, S., Bilitza, D., Heelis, R. A., and Rowland, D.: Performance of the IRI-2007 model for equatorial topside ion density in the African sector for low and extremely low solar activity, Adv. Space. Res., 52, 1780-1790, doi:10.1016/j.asr.2012.09.030, 2013.

Lean, J. L., Emmert, J. T., Picone, J. M., and Meier, R. R.: Global and regional trends in ionospheric total electron content, J. Geophys. Res., 116, A00H04, doi:10.1029/2010JA016378, 2011.

Lin, C. H., Hsiao, C. C., Liu, J. Y., and Liu, C. H.: Longitudinal structure of the equatorial ionosphere: Time evolution of the four-peaked EIA structure, J. Geophys. Res., 112, A12305, doi:10.1029/2007JA012455, 2007.

Liu, L., Le, H., Chen, Y., He, M., Wan, W., and Yue, X.: Features of the middle- and low-latitude ionosphere during solar minimum as revealed from COSMIC radio occultation measurements, J. Geophys. Res., 116, A09307, doi:10.1029/2011JA016691, 2011.

Picone, J. M., Hedin, A. E., Drob, D. P., and Aikin, A. C.: NRLMSISE-00 empirical model of the atmosphere: Statistical comparisons and scientific issues, J. Geophys. Res., 107, A121468, doi:10.1029/2002JA009430, 2002.

Pfaff, R., Rowland, D., Freudenreich, H., Bromund, K., Le, G., Acuña, M., Klenzing, J., Liebrecht, C., Martin, S., Burke, W. J., Maynard, N. C., Hunton, D. E., Roddy, P. A., Ballenthin, J. O., and Wilson, G. R.: Observations of DC Electric Fields in the Low Latitude Ionosphere and Their Variations with Local Time, Longitude, and Plasma Density during Extreme Solar Minimum, J. Geophys. Res., 115, A12324, doi:10.1029/2010JA016023, 2010.

Richards, P. G., Fennelly, J. A., and Torr, D. G.: EUVAC: A solar EUV Flux Model for aeronomic calculations, J. Geophys. Res., 99, 8981-8992, doi:10.1029/94JA00518, 1994.
Rishbeth, H. and Garriott, O. K.: Introduction to ionospheric physics, Academic Press, New York, NY, 1969.

Roble, R. G. and Ridley, E. C.: A thermosphere-ionospheremesosphere-electrodynamics general circulation model (TIMEGCM): equinox solar cycle minimum simulations $(30-500 \mathrm{~km})$, Geophys. Res. Lett., 21, 417-420, 1994.

Savitzky, A. and Golay, M. J. E.: Smoothing and differentiation of data by simplified least squares procedures, Anal. Chem., 36, 1627-1639, 1964.

Scherliess, L. and Fejer, B. G.: Radar and satellite global equatorial F region vertical drift model, J. Geophys. Res., 104, 6829-6842, 1999.

Simões, F., Pfaff, R., and Freudenreich, H.: Satellite observations of Schumann resonances in the Earth's ionosphere, Geophys. Res. Lett., 38, L22101, doi:10.1029/2011GL049668, 2011.

Simões, F., Klenzing, J., Ivanov, S., Pfaff, R., Freudenreich, H., Bilitza, D., Rowland, D., Bromund, K., Liebrecht, M. C., Martin, S., Schuck, P., Uribe, P., and Yokoyama, T.: Detection of ionospheric Alfvén resonator signatures in the equatorial ionosphere, J. Geophys. Res., 117, A11305, doi:10.1029/2012JA017709, 2012.

Solomon, S. C., Woods, T. N., Didkovsky, L. V., Emmert, J. T., and Qian, L.: Anomalously low solar extreme-ultraviolet irradiance and thermospheric density during solar minimum, Geophys. Res. Lett., 37, L16103, doi:10.1029/2010GL044468, 2010.

Solomon, S. C., Qian, L., Didkovsky, L. V., Viereck, R. A., and Woods, T. N.: Causes of low thermospheric density during the 2007-2009 solar minimum, J. Geophys. Res., 116, A00H07, doi:10.1029/2011JA016508, 2011.

Su, S.-Y., Liu, C. H., Ho, H. H., and Chao, C. K.: Distribution characteristics of topside ionospheric density irregularities: Equatorial versus midlatitude regions, J. Geophys. Res., 111, A06305, doi:10.1029/2005JA011330, 2006.

West, K. H. and Heelis, R. A.: Longitude variations in ion composition in the morning and evening topside equatorial ionosphere near solar minimum, J. Geophys. Res., 101, 7951-7960, 1996.

West, K. H., Heelis, R. A., and Rich, F. J.: Solar activity variations in the composition of the low latitude ionosphere, J. Geophys. Res., 102, 295-305, doi:10.1029/96JA03031, 1997.

Yue, X., Schreiner, W. S., Lei, J., Sokolovskiy, S. V., Rocken, C., Hunt, D. C., and Kuo, Y.-H.: Error analysis of Abel retrieved electron density profiles from radio occultation measurements, Ann. Geophys., 28, 217-222, doi:10.5194/angeo-28-217-2010, 2010. 